\title{
Experimental study on heat transfer enhancement caused by the flow-induced vibration of a prism inside a channel
}

\author{
F. Sastre, A. Velazquez*
}

Keywords:

Heat transfer enhancement

Confined laminar flow

Passive system

Flow induced vibrations

\begin{abstract}
A B S T R A C T
An experimental study, using water as the working fluid, has been performed to analyze whether a passive system based on flow-induced vibration is a feasible option to enhance heat transfer in the laminar confined regime. The experimental setup consisted of a $1.5 \mathrm{~m}$ tall vertical channel manufactured on methacrylate (square cross-section of $25 \mathrm{~mm} \times 25 \mathrm{~mm}$ ) and a tethered square section buoyant prism $(10 \mathrm{~mm} \times 10 \mathrm{~mm} \times 25 \mathrm{~mm})$ placed inside the channel. The tethered prism was allowed to move freely (like an inverted pendulum) as a consequence of its interaction with the incoming flow. An aluminum block placed in the channel walls around the prism heated the water with a constant wall temperature of $60 \mathrm{C}$. The flow Reynolds number (Re) based on the prism cross section length was varied between 80 and 800 . Three prisms with three different prism-to-water density ratios $\left(\mathrm{m}^{*}\right)$ were used in the experiments: $0.56,0.70$ and 0.91 . The case with the prism anchored to the walls was considered also. Regarding heat transfer, all cases were compared to the reference case which consisted of the clean channel with no prism present. The flow velocity was characterized using a Particle Image Velocimetry System. The electric power supply to the heated walls was recorded and the spatial distribution of water temperature was measured in a transversal plane downstream of the heated walls. It was found that the heat transfer enhancement provided by this system, as compared to the clean channel with no prism present, was very much dependent on Re. For example, at the lowest Re 80, the improvement on the Nusselt number $(\mathrm{Nu})$ was negligible for all cases. At highest $\mathrm{Re} 800$, the improvement on $\mathrm{Nu}$ was $100 \%$ for the case of prism-to-water density ratio of 0.91 , and $66 \%$ for the case of the prism anchored to the walls. This suggests that, when thinking of practical engineering applications, passive systems based on flow-induced vibration might represent a feasible alternative, because of its simplicity, to active systems that require a more complex implementation that includes a motor to move the prism. The simplest setup (the prism anchored to the walls) also yields a significant, if smaller, heat transfer enhancement.
\end{abstract}

c 2017 Elsevier Ltd. All rights reserved.

\section{Introduction}

Heat transfer enhancement in confined flows by means of using moving devices is very active area of research. The reason is that, in addition to its relevance as a basic thermal-fluid problem, this R\&D

\footnotetext{
* Corresponding author.

E-mail address: angel.velazquez@upm.es (A. Velazquez).
}

field has practical applications for several industrial sectors such as, for example, chemical engineering, energy, food processing, etc. The interest grows larger whenever laminar flows are involved because diffusion, that is a slow process, tends to dominate heat transfer in this regime. Then, it is of interest to devise new methods that target heat transfer enhancement in this type of flow regimes.

A very illustrative example of the type of work that is normally carried out in this field can be found in the article published by 
Celik et al. [1]. In their 2D numerical study, the authors considered a straight channel with a circular cylinder placed on its centerline. The blockage ratio of the configuration was 1:3. A uniform heat flux was applied to the channel walls while the cylinder itself was assumed to remain adiabatic. The flow Reynolds number $(R e)$, based on the cylinder diameter was 100 and the Prandlt number $(P r)$ was varied in the range between 0.1 and 100. First, the authors addressed the case of the fixed (unmoving) cylinder so as to compute in this case the frequency of the downstream shed vortices (the reference frequency). Next, they prescribed a harmonic cross flow wise motion of the cylinder and computed the downstream Nusselt number $(\mathrm{Nu})$. The frequencies that they prescribed were close to the reference frequency. Their findings for $P r=5$ (that is the case closest to considering water as the working fluid) were as follows: (a) the limiting $\mathrm{Nu}$ in the case of the clean channel with no cylinder present was 14 , (b) the limiting $N u$ in the case of the cylinder moving with a frequency of 0.75 times the reference frequency was 17.5 (a 25\% improvement), and (c) prescribing frequencies above the reference frequency did not improve heat transfer or even deteriorated it. All this was regarding the limiting $\mathrm{Nu}$ in the region far downstream of the cylinder. In the region close to the cylinder, local heat transfer enhancement was larger (close to a $50 \%$ of improvement). Another numerical 2D study has been reported by Fu and Tong [2]. In this case, the authors considered three different blockage ratios, $1: 8,1: 4$, and $1: 2$ for different combinations of frequency and amplitude of the cylinder motion at Re 500 based on the channel height (the working fluid was air). In yet another study, Fu and Tong [3], performed comparisons in terms of the average $\mathrm{Nu}$. In a short channel section downstream of the cylinder, heat transfer associated to the moving cylinder improved by a factor of $31 \%$ the heat transfer rate of the clean channel (no cylinder present). When averaging the $\mathrm{Nu}$ over the whole channel, the improvement was $23 \%$. So these conclusions are qualitatively and quantitatively similar to those already mentioned of Celik et al. [1].

Yang and Chen [4] have presented another 2D numerical study in which four heated blocks were attached to walls of a channel in which a cylinder was moving with prescribed frequencies and amplitudes. The aspect ratio of the blocks was $1: 4$ and $R e$ was higher than in previous references $(800-8000$ based on the cylinder diameter). The working fluid was also air. Depending on the selected frequencies and amplitudes of the cylinder motion, heat transfer rate improvements (defined as the space-time averaged $\mathrm{Nu}$ in the case with cylinder versus the case without cylinder) ranged from $8 \%$ to $17 \%$. The case in which the cylinder itself is the heated element and its motion is used to enhance heat transfer from the cylinder to the surrounding fluid has also been studied extensively. For some examples, the interested reader is referred to the works of Ghazanfarian and Nobari [5], Nobari and Ghazanfarian [6] and Pottebaum and Gharib [7].

In all the references mentioned previously, the cylinder motion was prescribed (an active system). It means that in an actual engineering situation some kind of motor with an associated mechanism has to be used. This, by itself, might be difficult, in particular when dealing with mini/micro systems. It might also be prone to suffer from functioning problems such as leakages, motor failures, etc. In this context, the objective of the present article is to study whether a very simple passive system in which the prism motion is self-generated and self-sustained might provide some acceptable enhancement of the heat transfer rate from the channel walls into the fluid. Specifically, this self-sustained motion occurs because of the interaction between the incoming flow and the cylinder (the phenomenon called flow induced vibration). In this way, the system design and actuation is much simpler (it is, for instance, water tight) which may facilitate its actual use in industrial applications. Regarding the basic fluid mechanics aspects of this problem, the reader is referred to the isothermal experimental studies published by Reyes et al. [8] and Reyes et al. [9]. In these two studies, detailed Particle Image Velocimetry (PIV) based analysis were presented on the flow topology past a fixed square section prism and a free prism allowed to move unhindered in the crossflow direction inside a square section channel. The different flow regimes were analyzed and it was found that, depending on the Re and on the body to fluid density ratio (the body was buoyant), both periodic and chaotic flow conditions could be observed. Now, in the present article, the objective is to move one step ahead by way of including thermal effects so as to find out whether these flow regimes might enhance the mixing of a passive scalar such as temperature.

Regarding to the article organization, the experimental set-up is described first. Then, the experimental campaigns are defined and the results are presented and discussed. Finally, conclusions are presented.

\section{Description of the experimental setup and measurement systems}

The experimental setup had the form of a closed loop circuit, see Fig. 1. The main parts of the setup were: the test channel, the test section, the power supply unit, three tanks, a flow meter, a pump, and a radiator to prevent the recirculating water from overheating (before entering the main tank, water temperature was monitored to be constant at the level of $25 \mathrm{C}$ ).

\subsection{The test channel}

It was manufactured in methacrylate and it was placed vertically. Its square cross section was $25 \mathrm{~mm} \times 25 \mathrm{~mm}$. Its total height was $1490 \mathrm{~mm}$. The thickness of the channel walls was $10 \mathrm{~mm}$. The channel was inserted into a large primary tank where the flow was homogenized. To achieve further homogenization, so as to shorten as much as possible the hydrodynamic entrance length, a honeycomb section was inserted at the entrance of the test channel (the inflow section). The outflow section discharged into a secondary tank where the water level remained constant; the idea being to avoid pressure fluctuations in the test section of the channel. A view of the channel together with information on the location of the origin of coordinates and all associated distances is presented in Fig. 2.

\subsection{The test section}

The heated test section was $90 \mathrm{~mm}$ long and it was located midway along the channel (see Fig. 2). It consisted of a hollow aluminum block, where the tethered prism was inserted, located a distance $950 \mathrm{~mm}$ away from the channel inflow section (see Fig. 2). A close-up view of this test section is shown in Fig. 3.

The thickness of the aluminum walls was $15 \mathrm{~mm}$. These walls were externally insulated with $10 \mathrm{~mm}$ thick methacrylate panels to minimize thermal losses. A simple thermal model was developed that showed that, because of the methacrylate very low thermal conductivity and its thickness, losses to the outside ambient air were negligible compared to the thermal power transferred to the fluid. 16 electrical cartridges ( 4 per side) were inserted into the aluminum block to provide controlled heating. 10 T-type thermocouples were inserted into the aluminum to monitor its temperature spatial distribution. The objective being to keep a constant wall temperature of about $60^{\circ} \mathrm{C}$. All the 16 cartridges were fed with a DC power supply, whose output voltage was be controlled via a PID based control system. Because of the ascending thermal boundary layer, the two upper rows of cartridges were 


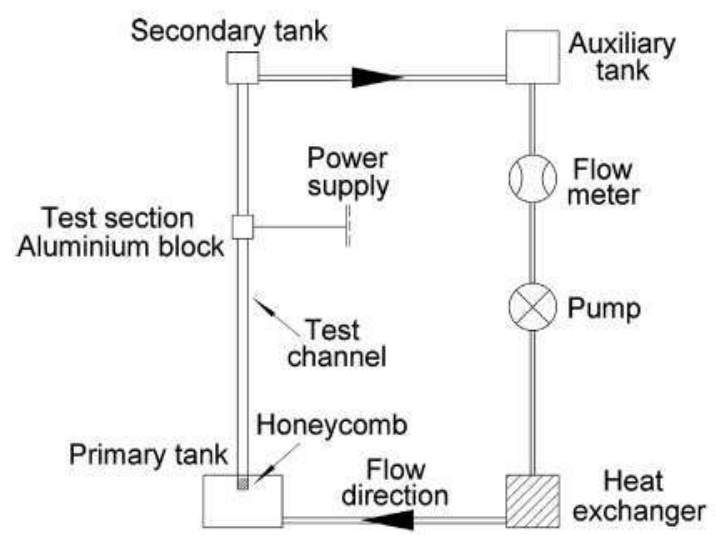

Fig. 1. Sketch of the experimental setup.

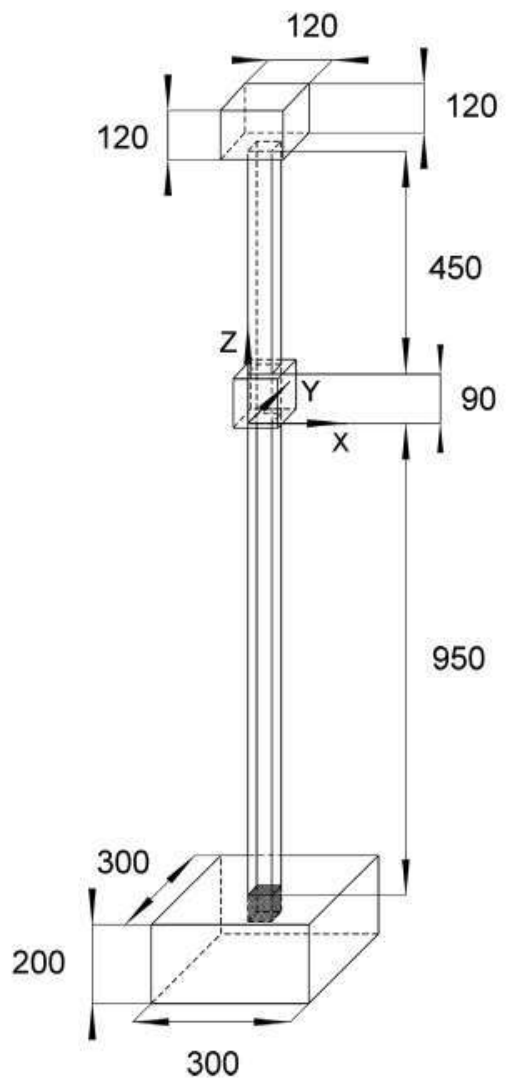

Fig. 2. View of the test channel and primary (bottom) and secondary (top) tanks. The heated section ( $90 \mathrm{~mm}$ height) can be observed midway along the channel where the origin of coordinates is placed. Distances are expressed in $\mathrm{mm}$. powered with a square wave, controlling its duty cycle using a relay, so as to maintain a uniform wall temperature. Table 1 shows the time-averaged temperatures measured by the 10 thermocouples ( $\mathrm{T} 1$ to $\mathrm{T} 10$ ), and both the standard and maximum temperature deviations for the case of the fixed (unmoving) prism for some representative $R e$. The coordinates of the inserts were the thermocouples were placed are also given in Table 1 (notice that some coordinates are negative and some other larger than $25 \mathrm{~mm}$ because these thermocouples were placed inside the aluminum walls and they were not in contact with the fluid). The thermocouples were of the Tcdirect brand and they measured with an uncertainty of $\pm 0.5 \mathrm{C}$. They were connected to a NI9214 data acquisition system with a sensibility of $\pm 0.02 C$. At the lowest $R e$, the maximum spatial temperature deviation between thermocouples was of the order of $1 \mathrm{C}$. This deviation was of the order of $45 \mathrm{C}$ at the highest Reynolds number.

Nine additional temperature measurement points were placed in a plane located $20 \mathrm{~mm}$ downstream of the aluminum block ( $60 \mathrm{~mm}$ downstream of the prism), see Fig. 3, to measure the spatial distribution of water temperature inside the channel. To minimize flow disturbances, these temperatures were acquired one by one using a sequential procedure. Specifically: each single thermocouple was inserted through the channel wall into the flow field, was allowed to measure and, then, retrieved. The inserts were sealed with plastic material to prevent leaking. The process was sequentially repeated for all 9 measurement locations. Fig. 4 shows the actual spatial locations where the thermocouples were inserted. The view is from the top of the channel down towards the test section; this why the prism (shaded in grey color) is also seen in the figure. Finally, an actual photograph of test section together with some of the prisms used in the experiments are presented in Fig. 5.

Regarding the prisms, they were hollowed out when manufactured so as to achieve different density ratios, $m^{*}$. Specifically, three prisms with the following $\mathrm{m}^{*}$ were manufactured: 0.56 , 0.70 and 0.91 .

\subsection{Auxiliary systems}

The flow meter was an electromagnetic Siemens Sitrans FM MAG1100 equipped with a Sitrans FM MAG5000 transmitter. The measurement range was from 0 to $51 / \mathrm{min}$ and the uncertainty was $\pm 5 \%$. The pump was an ITT Totton centrifugal with a magnetic drive DC15/5. An overview picture of the whole experimental setup is presented in Fig. 6.

\subsection{The Particle Image Velocimetry (PIV) system}

This PIV system was from Dantec Dynamics. Flow illumination was achieved with a pulsed Nd:YAG $800 \mathrm{~mJ}$ Laser. The time lapse between two laser pulses (needed to collect a single sample) was
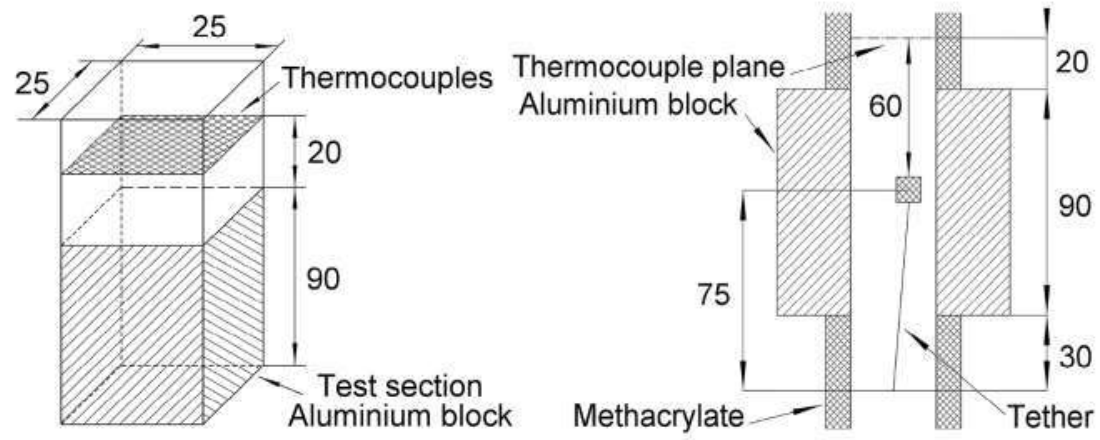

Fig. 3. Close-up view of the test section (left) and of the centerline plane (right). Distances are expressed in $\mathrm{mm}$. 
Table 1

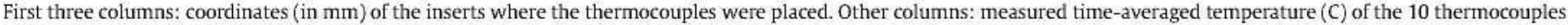

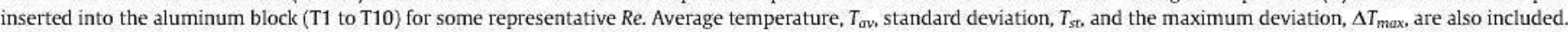

\begin{tabular}{|c|c|c|c|c|c|c|c|c|c|}
\hline & \multirow[b]{2}{*}{$\mathrm{x}$} & \multirow[b]{2}{*}{ y } & \multirow[b]{2}{*}{$z$} & \multicolumn{6}{|l|}{$\operatorname{Re}$} \\
\hline & & & & $\begin{array}{l}80 \\
T(C)\end{array}$ & 133 & 260 & 360 & 466 & 733 \\
\hline $\mathrm{T} 1$ & 12.5 & -1.0 & 70.0 & 58.8 & 57.8 & 58.6 & 59.3 & 58.9 & 53.1 \\
\hline $\mathrm{T} 2$ & 12.5 & 26.0 & 70.0 & 58.7 & 57.8 & 58.1 & 58.8 & 58.4 & 52.7 \\
\hline T3 & 12.5 & -1.0 & 25.0 & 58.9 & 58.2 & 58.9 & 59.4 & 59.8 & 55.0 \\
\hline T4 & 12.5 & 26.0 & 25.0 & 58.7 & 58.0 & 58.5 & 59.2 & 59.4 & 54.7 \\
\hline $\mathrm{T} 5$ & 26.0 & 12.5 & 70.0 & 58.4 & 57.3 & 57.1 & 57.5 & 57.0 & 50.8 \\
\hline T6 & -1.0 & 12.5 & 70.0 & 58.5 & 57.4 & 57.5 & 57.4 & 56.9 & 50.7 \\
\hline T7 & 26.0 & 12.5 & 45.0 & 59.5 & 58.8 & 59.0 & 59.3 & 59.1 & 53.2 \\
\hline T8 & -1.0 & 12.5 & 45.0 & 59.6 & 58.7 & 59.2 & 59.5 & 59.0 & 53.4 \\
\hline T9 & 26.0 & 12.5 & 20.0 & 58.9 & 58.2 & 58.7 & 59.4 & 59.8 & 55.1 \\
\hline T10 & -1.0 & 12.5 & 20.0 & 59.5 & 58.5 & 59.1 & 59.8 & 60.0 & 55.4 \\
\hline$T_{a v}$ & & & & 59.0 & 58.1 & 58.5 & 59.0 & 58.8 & 53.4 \\
\hline$T_{S t}$ & & & & 0.4 & 0.5 & 0.7 & 0.8 & 1.1 & 1.7 \\
\hline$\Delta T_{\max }$ & & & & 1.2 & 1.5 & 2.1 & 2.3 & 3.2 & 4.7 \\
\hline
\end{tabular}

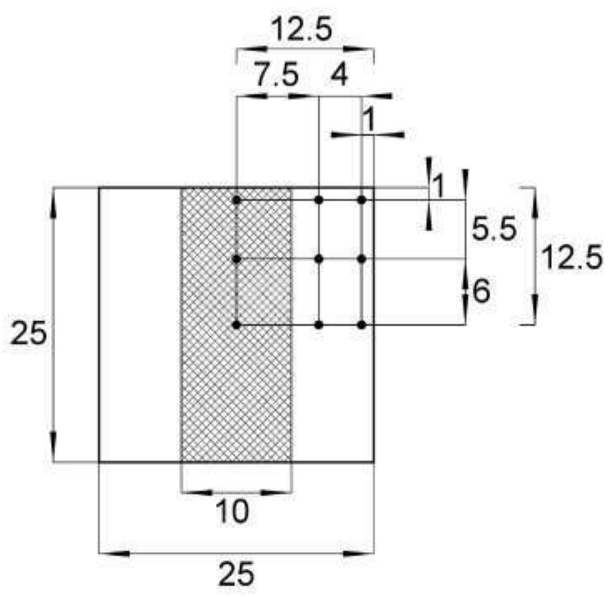

Fig. 4. Position of the 9 points (located downstream of the aluminum block) where water temperature is measured. The view is from the top of the channel into the test section. The prism is shaded in a darker grey mesh. Measurements are expressed in $\mathrm{mm}$.

$5 \mathrm{~ms}$. At the maximum flow velocity used in the experiments, a particle would travel $0.3 \mathrm{~mm}$ between pulses that is a distance much smaller than the problem characteristic length of $10 \mathrm{~mm}$ (the prism cross section length). The camera was a Dantec Dynam- ics Flow Sense $2 \mathrm{ME}$ with a resolution of $1600 \times 1200$ pixels. The lens was a Zeiss Makro-Planar $\mathrm{T}^{*} 2 / 50 \mathrm{~mm}$ ZF. Flow seeding was performed with $10 \mu \mathrm{m}$ hollow glass spheres (HGS-10). Dantec Dynamics Studio software was used to synchronize image capturing and flow illumination, and to perform the analysis. The size of the interrogation areas was $50 \mathrm{~mm} \times 25 \mathrm{~mm}$. These areas were subdivided into smaller areas by the analysis software to achieve convergence in the re-computation process of the flow field. It was estimated that the spatial resolution of the flow field was of the order of $1 \mathrm{~mm}$ that should be enough to capture the large flow structures whose size was of the order of the prism cross-section length $(10 \mathrm{~mm})$. The sampling frequency was $15 \mathrm{~Hz}$. Afterwards, it was found that the relevant flow frequencies were of the order of $1 \mathrm{~Hz}$, so the temporal resolution of the experimental setup was adequate to capture the relevant flow features.

\section{Definition of the experimental campaigns}

Six different experimental campaigns (EC) were carried out in the present study. They were labeled EC \#1 to EC \#6. Their definition is as follows:

- EC \#1. Clean channel with no prism present. Isothermal walls. $R e$, based on a characteristic length of $1 \mathrm{~cm}$ (the prism cross section length in the cases where the prism is present) equal to: 80 , $160,200,240,320,400,600$, and 800 . The lowest volume flow
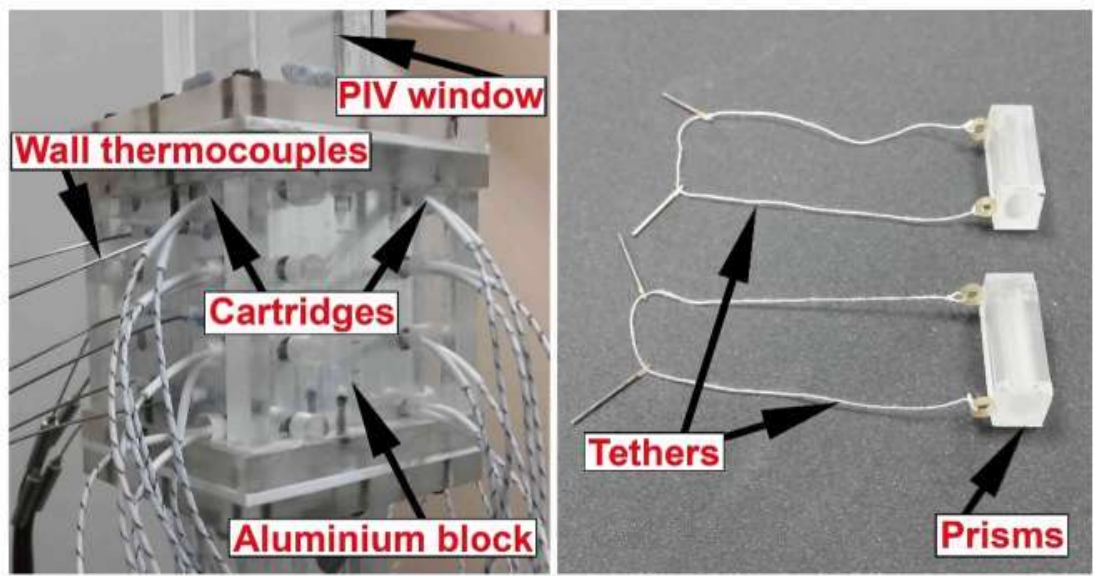

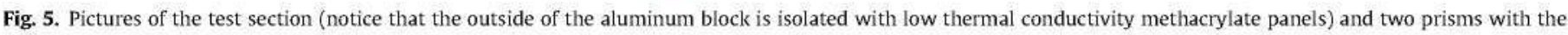
attached tethers. 


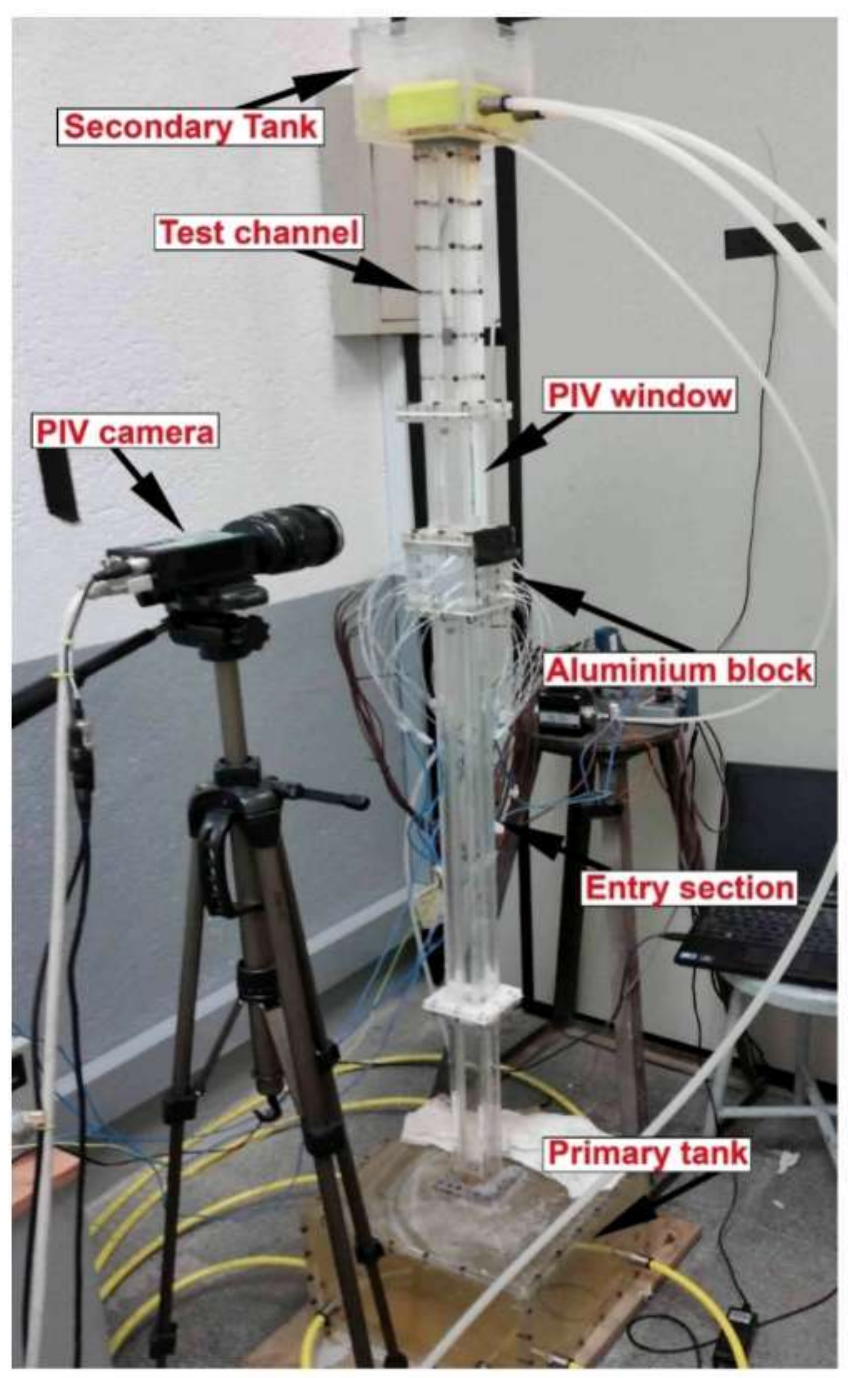

Fig. 6. Overview of the experimental setup.

rate corresponding to $\operatorname{Re} 80$ was $0.268 \mathrm{l} / \mathrm{min}$ (average inlet velocity equal to $0.007 \mathrm{~m} / \mathrm{s}$ ). The largest volume flow rate corresponding to Re 800 was $2.68 \mathrm{1} / \mathrm{min}$ (average inlet velocity equal to $0.070 \mathrm{~m} / \mathrm{s}$ ).

- EC \#2. Clean channel with no prism present. Walls heated to the temperature level specified in Table 1 . The Re range equal to that of EC \#1.

- EC \#3. Channel with prism anchored to the walls (no prism motion allowed). Isothermal walls. $R e$ (based on the prism cross section length of $1 \mathrm{~cm}$ ) equal to: $80,106,133,160,200,240$, $260,280,300,320,360,400,466,533,600,666,733$, and 800 .

- EC \#4. Channel with prism anchored to the walls (no prism motion allowed). Walls heated to the temperature levels specified in Table 1. The range of Re equal to that of EC \#3.

- EC \#5. Channel with tethered prism placed inside and allowed to move freely. Isothermal walls. The range of Re equal to that of EC \#3. Three different prisms to water density ratios were considered for each case: $0.56,0.70$ and 0.91 .

- EC \#6. Channel with tethered prism allowed to move freely. Walls heated to the temperature levels specified in Table 1. The range of Re equal to that of EC \#3. Three different prisms to water density ratios were considered for each case: 0.56 , 0.70 and 0.91 .

Accordingly, the total number of experimental cases addressed in the study was 160 (EC \#1: 8 cases, EC \#2: 8 cases, EC \#3: 18 cases, EC \#4: 18 cases, EC \#5: 54 cases, EC \#6: 54 cases). A limited set out of these 160 cases was selected for the repeatability tests. The outcome of these repeatability tests will be described in the following sections.

\section{Results}

\subsection{EC \#1 campaign}

This campaign could be considered as the setup calibration campaign because results were compared to those obtained theoretically by [10] for laminar flow in a square section channel. This is observed in Fig. 7 where the average value of the 100 measured velocity profiles, their maximum spread, and the theoretical profiles are presented. Out of the whole set of results, four Reynolds numbers $(80,160,240$, and 320 ) were selected for illustration purposes in Fig. 7. In these cases, the flow is hydrodynamically developed before reaching the measurement section so that comparison with the theoretical results of [10] can be consistently performed.

Regarding the spread of the measurements, see the gray shaded bands in Fig. 7, the histogram presented in Fig. 8 shows a typical distribution of the 100 centerline velocity measurements around the mean (the case of $\operatorname{Re} 160$ has been chosen for illustration purposes).

\subsection{EC \#2 campaign}

This case is like the previous one but for the fact that the aluminum block is heated up to a constant temperature of $60 \mathrm{C}$. The counterpart of Fig. 7 for this case is presented in Fig. 9. There, it could be observed that at the lower $R e$, buoyancy dominates the velocity profiles (notice the high velocity plumes ascending close to the walls at $\mathrm{y} / \mathrm{c}=0$ and $\mathrm{y} / \mathrm{c}=1)$. As the Re increases, this effect losses its importance until the convection from the main body of fluid dominates again the velocity profile (except in a small region close to the walls) at $\operatorname{Re} 320$.

The temperature information obtained from the thermocouples inserted in the flow field in the transversal plane located $20 \mathrm{~mm}$ downstream of the aluminum block was processed, using a nearest neighbor algorithm [11] together with symmetry considerations, to reconstruct the temperature field in that plane. An example of this reconstruction for $\operatorname{Re} 80$ and $\operatorname{Re} 320$ is presented in Fig. 10. These temperature planes will be used in the next sections to assess the degree of mixing in the flow field.

The Nusselt number, $\mathrm{Nu}$, in this thermal case is defined as: $N u=h L / k_{\text {film }}$ where $h, L$, and $k_{\text {film }}$ are the convection heat transfer coefficient, the characteristic length, and the water thermal conductivity at the film temperature. The characteristic length for $\mathrm{Nu}$ was taken to be the hydraulic diameter of the channel $(0.025 \mathrm{~m})$. The film temperature was defined as:

$$
T_{\text {film }}=\frac{\frac{T_{\text {in }}+T_{\text {out }}}{2}+T_{\text {wall }}}{2}
$$

where $T_{\text {in }}, T_{\text {out }}$, and $T_{\text {wall }}$ were inlet, outlet, and wall temperature respectively. $T_{\text {in }}$, and $T_{\text {wall }}$ were measured directly. The fluid temperature downstream of the heated section, $T_{\text {out }}$, was computed by means of an energy balance: $\dot{Q}_{\text {in }}+H_{P}=\dot{Q}_{\text {out }}$, where $\dot{Q}_{\text {in }}$ and $\dot{Q}_{\text {out }}$ where the thermal energy per unit time entering and leaving the test section respectively, and $H_{P}$ was the measured electrical heating power. Then, $h$ was computed by performing the following balance:

$$
H_{p}=h A_{h w}\left(T_{\text {wall }}-\frac{T_{\text {in }}+T_{\text {out }}}{2}\right)
$$


$\operatorname{Re} 80$

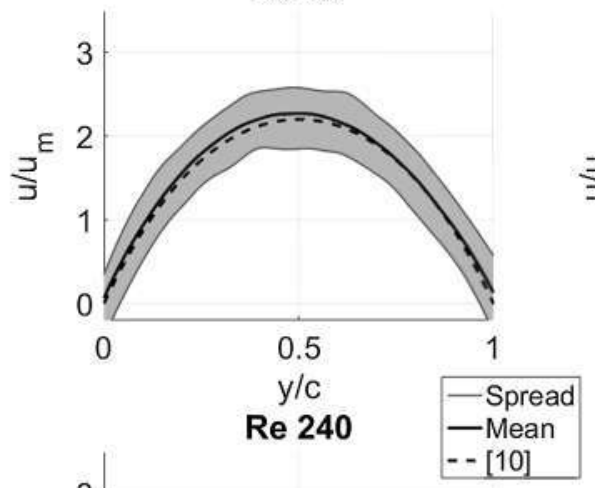

$\operatorname{Re} 160$

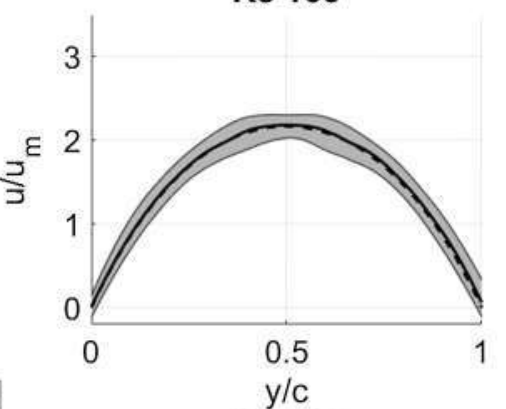

$\operatorname{Re} 320$
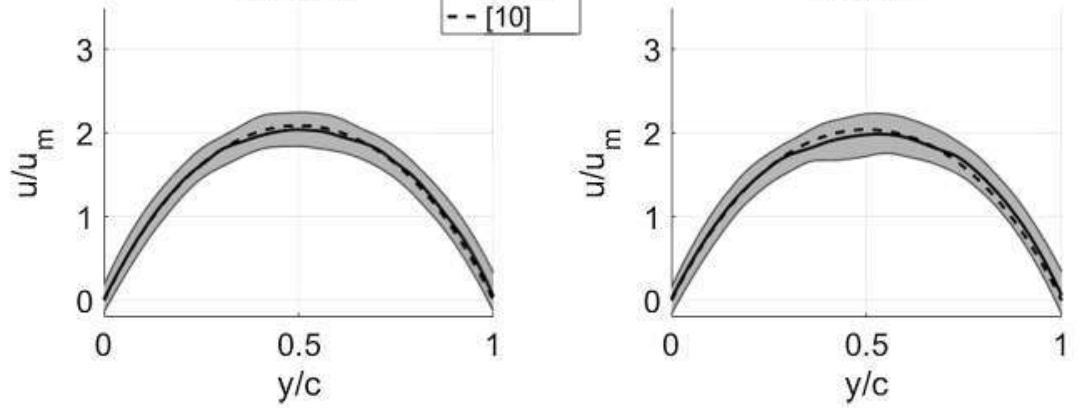

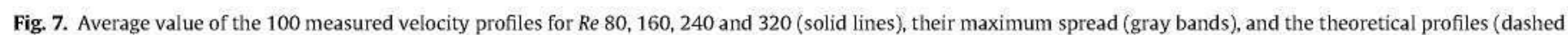
lines).

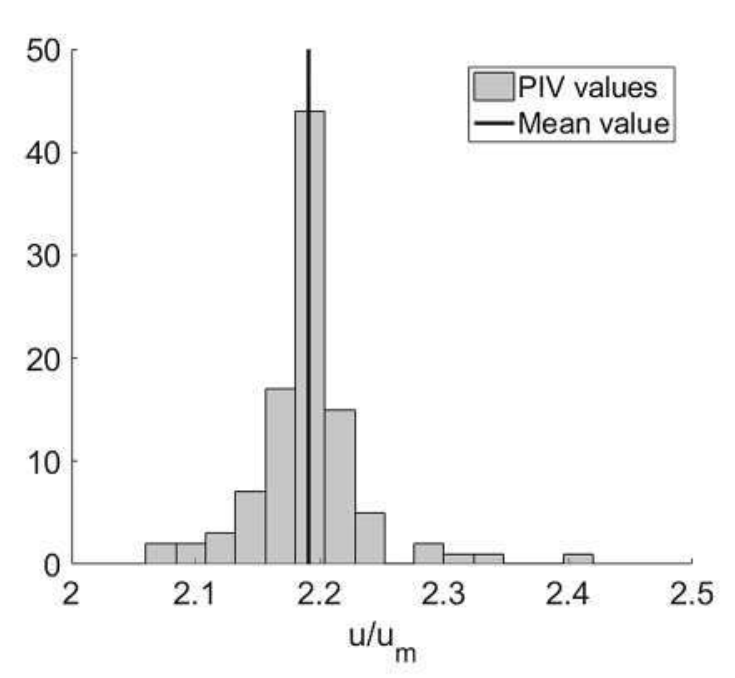

Fig. 8. Histogram of the 100 centerline velocity measurements around the mean for Re 160.

where $A_{h w}$ was the heated wall area. Once $h$ and $T_{\text {film }}$ were obtained in this way, the Nusselt number was computed.

$H_{p}$ (i.e.: the thermal power supplied to the flow of water to keep the aluminum block at a constant temperature of $60 \mathrm{C}$ ) and $\mathrm{Nu}$ as a function of $\mathrm{Re}$ are presented in Table 2 . There, it could be observed that this power supply was nearly constant in the range from $R e 80$ to 600 ( $R e 200$ to 1500 if based on the channel hydraulic diameter) which suggests that $\mathrm{Nu}$ is constant (as it could be observed in Table 2). This is in line with the well-known theoretical result [12] that states that the $\mathrm{Nu}$ in a heated square/rectangular channel in the laminar regime does not depend on the Re. It is to be noted that the $\mathrm{Nu}$ as given in reference [12] for a square section channel in the laminar regime is 3.6 . However, that result is for a hydrodynamically and thermally developed flow, and with heat transfer being applied along all channel walls, which is not the case addressed in the present study; thereby the differences in $\mathrm{Nu}$ values. Given the uncertainty associated to the measurements of the thermocouples and the power unit, it was estimated that the typical uncertainty in the computed $\mathrm{Nu}$ was of the order of $\pm 5 \%$.

\subsection{EC \#3 and EC \#5 campaigns}

These two campaigns correspond to the isothermal case with prism present. In particular, in EC \#3 the prism is anchored to the channel walls, while in EC \#5 it is tethered and allowed to move. Flow characterization was carried out using the PIV system described in Section 2.4. The sketch of the actual PIV interrogation window integrated into the experimental result is presented in Fig. 11. It could be observed that this window is located $60 \mathrm{~mm}$ ( 6 diameters) downstream of the prism. This is so because the prism is enclosed in between solid aluminum walls that do not allow for PIV sensing. This means that the flow structures that can be actually sensed are, at least, at a distance of six diameters away from the prism. Furthermore, given the fact that the flow is highly confined, these structures are likely to be smeared out as a consequence of the strong interactions taking place and the viscous effects enhanced by the nearby walls.

The solid to fluid mass ratio $\mathrm{m}^{*}$ influences the prism motion and, as a consequence, the flow field topology downstream of the prism and the associated mixing. This is apparent when the prism equations of motion are written, see Fig. 12.

The two equations of motion in the limit $\alpha \ll 1(\cos (\alpha) \cong 1, \sin (\alpha) \cong \alpha)$ are:

$B+F_{C d}=T$

$F_{C I}-T \alpha=m_{P} \frac{d^{2} \alpha}{d t^{2}} L_{T h}$

where $B, F_{C d}, T, F_{C l}, \alpha, m_{P}, t, L_{T h}$ are buoyancy force, drag force, tether tension, lift force, angle of motion, prism mass, time and tether length. Introducing $T$ from Eq. (3) into Eq. (4) yields:

$F_{C l}-\left(B+F_{C d}\right) \alpha=m_{P} \frac{d^{2} \alpha}{d t^{2}} L_{T h}$ 
$\operatorname{Re} 80$
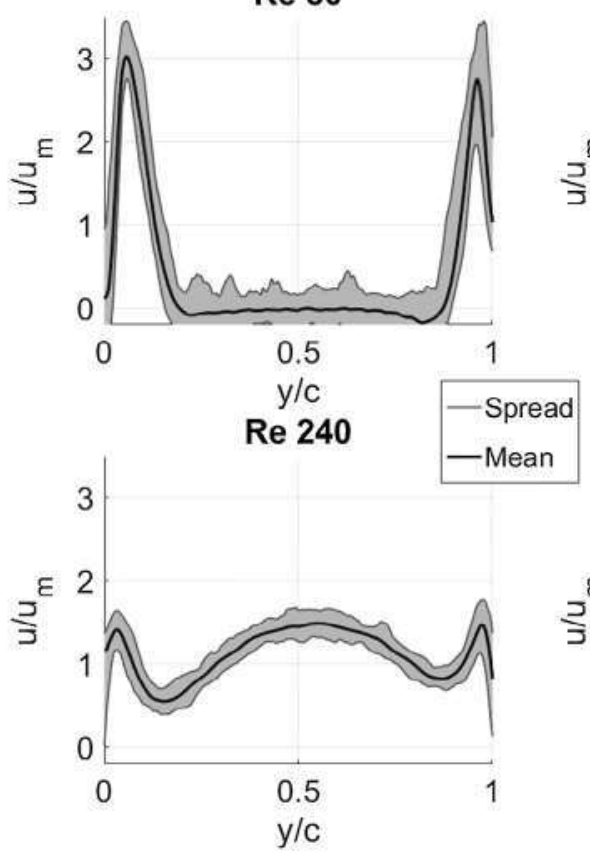

$\operatorname{Re} 160$

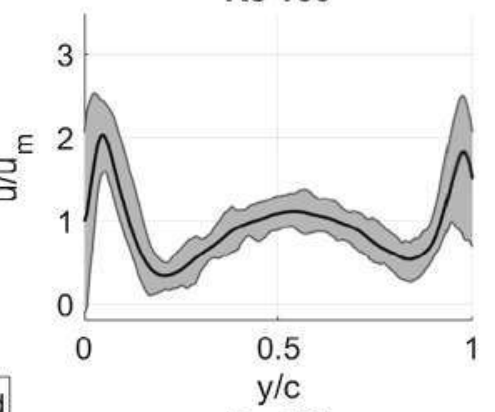

$\operatorname{Re} 320$

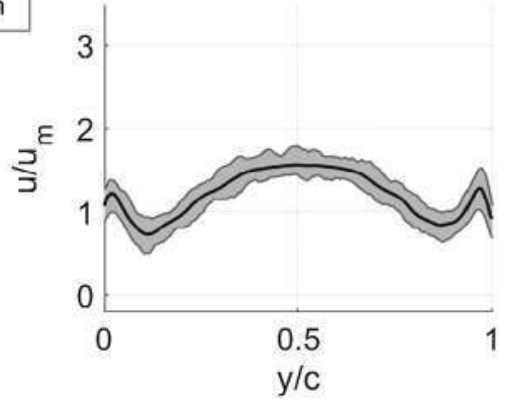

Fig. 9. Counterpart of Fig. 7 for the case of heated walls (no theoretical results are available in this case).

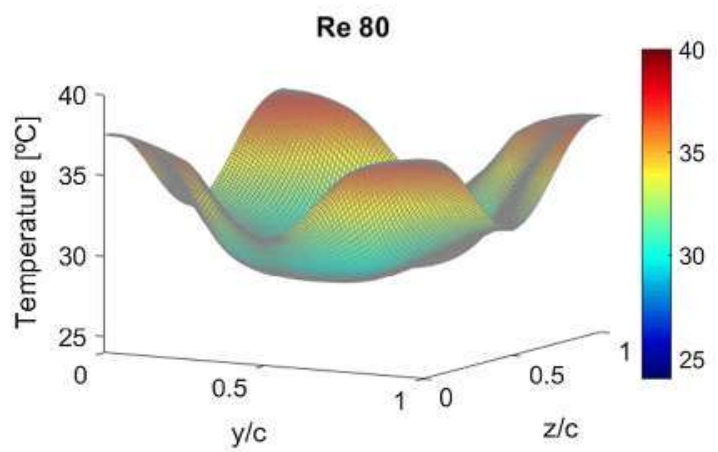

$\operatorname{Re} 320$

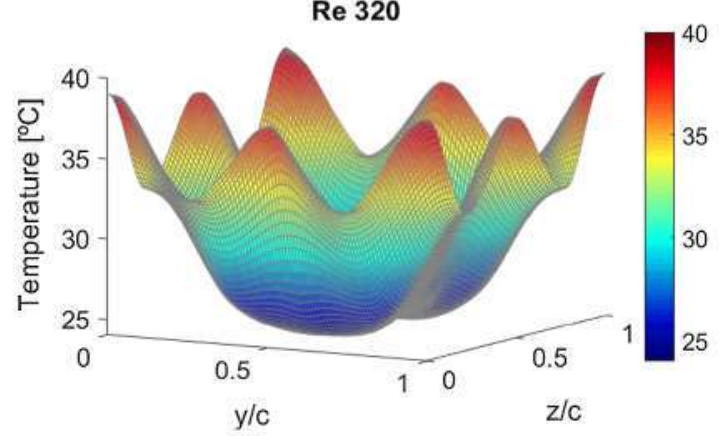

Fig. 10. Reconstructed temperature field in a plane located $20 \mathrm{~mm}$ downstream of the aluminum block for Re 80 and 320 .

That is: the buoyancy force $B$, that depends directly on the solid to fluid mass ratio $\mathrm{m}^{*}$, enters the prism equation of motion in such a way that the lower $\mathrm{m}^{*}$ the larger $B$, and, therefore, the larger the restoring force $T \sin (\alpha) \cong T \alpha$. For the cases considered in the experiments, the maximum values of $\alpha$ obtained were of the order of $0.05 \mathrm{rad} \ll 1 \mathrm{rad}$, so the approximate Eqs. (3)-(5) hold to a reasonable degree of accuracy. In practice, different values of $\mathrm{m}^{*}$ could be
Table 2

Measured electric power supply and $\mathrm{Nu}$ as a function of Re for experimental campaign EC \#2.

\begin{tabular}{lll}
\hline Re & $H_{p}(\mathrm{~W})$ & $\mathrm{Nu}$ \\
\hline 80 & 214 & 32.0 \\
160 & 215 & 32.0 \\
240 & 214 & 31.9 \\
320 & 214 & 31.8 \\
400 & 219 & 31.8 \\
600 & 220 & 31.7 \\
\hline
\end{tabular}

obtained using different materials for the manufacturing of the prism although, as described in Section 2.2, the method chosen is the present study was to use appropriately hollowed out cylinders of the same material.

The two horizontal dashed lines A and B in Fig. 11 above indicate the two specific locations that have been used for analysis purposes. In particular the downstream velocity has been time averaged and it is presented in Fig. 13 along these two lines for Re 200 and $\operatorname{Re} 733$ for both the fixed prism and the moving prism with $\mathrm{m}^{*}=0.91$. According to the results presented in reference [9] the case of $\operatorname{Re} 200$ corresponds to the flow regime in which the prism undertakes low frequency and moderately high amplitude oscillations with a well-defined Karman-type wake, while Re 733 corresponds to a chaotic regime.

When looking at the right hand side plot of Fig. 13 (section A of Fig. 11), it is apparent that at Re 200 and at a distance of 9 prism diameters downstream of the prism itself, the flow is close to attaining its limiting Poiseuille-type limiting behavior (the peak dimensionless velocity at the channel centerline should be 2.2 in fully developed flow). However, interestingly enough, the flow is closer to its limiting state in the case of the moving prism. In this case, the peak velocity is 1.96 while in the case of the fixed prism the peak velocity is 1.78 . This suggests that the flow topology induced by the moving prism contributes to homogenize the flow field somewhat faster than the flow topology induced by the fixed prism. In a sense, this result appears to contradict intuition because 


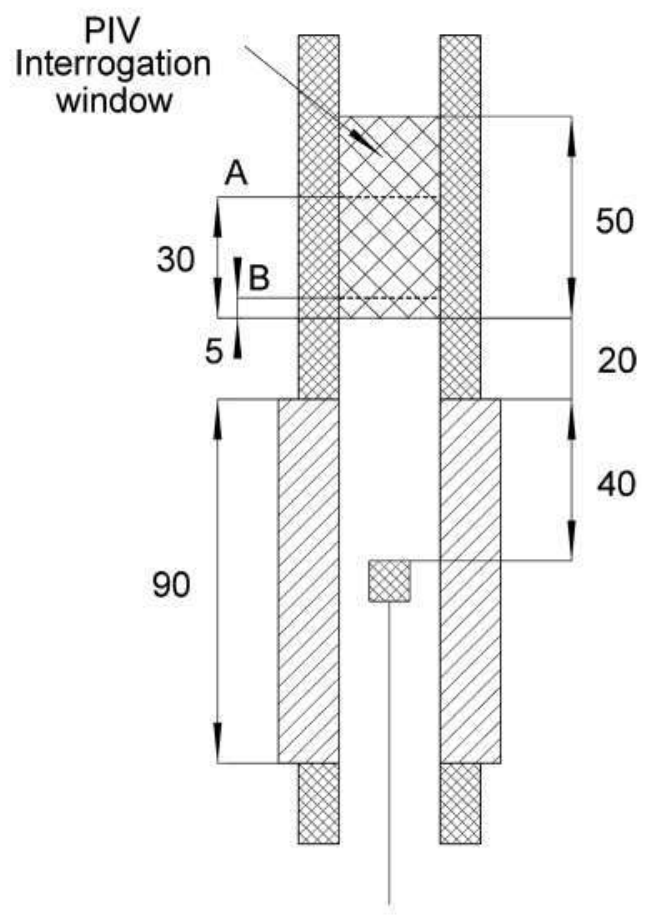

Fig. 11. Sketch showing the PIV interrogation window in the channel.

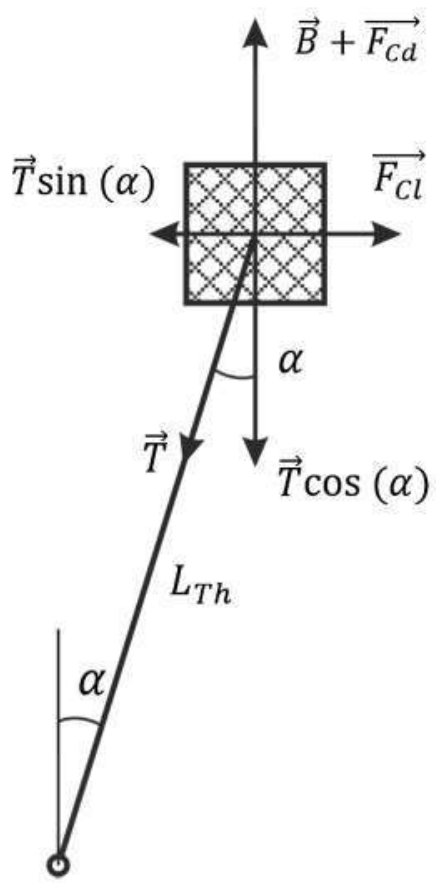

Fig. 12. Forces acting on the prism.

one would think that the large moving structures generated by the oscillating prism would require a longer channel length to attain their limiting state. However, this question is somewhat out of the main focus of the present article and it will be addressed by the authors in a future work. In the chaotic regime ( $\operatorname{Re} 733)$ the behavior is just the opposite: the flow generated by the fixed prism is closer to its limiting Poiseuille type limiting state. The results of section $B$ (located closer to the prism at a distance of 6.5 diameters in the downstream direction) are consistent with the results obtained for section $\mathrm{A}$.
The time averaging process was carried out at a frequency of $15 \mathrm{~Hz}$ during $20 \mathrm{~s}$. That is: 300 time frames were used to generate each of the curves presented in Fig. 13. The power spectral density plots of the points of each curve located at the channel centerline $(y / c=0.5)$ are presented in Fig. 14. It could be observed that at Re 200 the significant frequencies for the fixed prism were below $1 \mathrm{~Hz}$. For the case with $\mathrm{m}^{*}=0.91$, a distinct frequency appears at $2 \mathrm{~Hz}$. This also supports the idea that the sampling carried out at $15 \mathrm{~Hz}$ was consistent with the characteristic frequencies of the phenomena itself. In the case of $\operatorname{Re} 733$, the PSD plots show the typical flat appearance of the chaotic flow.

\subsection{EC \#4 and EC \#6 campaigns}

The counterpart of Fig. 13 for the thermal cases is presented in Fig. 15. It could be observed that, in this case, the flow profile at Re 200 is still dominated by buoyancy since the velocity in the region close to the walls is markedly higher than in the channel centerline. At Re 733 the opposite happens: velocity at the centerline is higher than in the near wall region. The PSD plots of these cases are presented in Fig. 16.

\section{Discussion}

The present work focuses on the question of whether a passive system whose motion is caused by fluid-body interaction is able to improve heat transfer significantly in practical engineering applications. In this view, Fig. 17 shows the summary of results regarding the electric power supply to the aluminum walls as a function of Re and $\mathrm{m}^{*}$ (including the fixed prism case) for constant wall temperature. For any given $\mathrm{m}^{*}$, the supplied power was increased along with Re to keep a constant aluminum wall temperature. The maximum available power delivered by the DC unit was $315 \mathrm{~W}$. This threshold level was achieved at $\operatorname{Re} 320$ for $\mathrm{m}^{*}=0.91$ and at $\operatorname{Re} 520$ for $\mathrm{m}^{*}=0.56$. For the case of the fixed prism the threshold level was also reached at $\operatorname{Re} 520$.

To quantify the different heat transfer rates, $\mathrm{Nu}$ as a function of $R e$ and $\mathrm{m}^{*}$ has been computed and the results are presented in Table 3. It could be observed that $\mathrm{Nu}$ grows along with $\mathrm{Re}$ and that the configuration that yields the higher $\mathrm{Nu}$ is the one with $\mathrm{m}^{*}=0.91$. These results correlate with the following expression: $\mathrm{Nu}=23.31 R e^{0.09} \mathrm{~m}^{* 0.22}$. As compared to the results presented in Table 2 (the clean channel) the maximum improvements are of the order of $36 \%$. It could be argued that this improvement comes at the expense of a higher pressure drop and, therefore, of a higher pumping power. This is true; however, it has been estimated that the pressure drop caused by the prism is negligible compared to the hydrostatic pressure difference in the vertical channel. In particular, the numerical simulations of Martin and Velazquez [13] show that for a fixed prism inside a channel with the same geometry and blockage ratio the total drag coefficient is 4.8 at $R e=100$. This yields a dimensional pressure drop of about $0.25 \mathrm{~Pa}$ that is not feasible to measure with standard laboratory equipment (measurement uncertainties of $\pm 50 \mathrm{~Pa}$ are typical for this type of pressure sensors).

As already mentioned, the results presented in Fig. 17 and Table 3 show that the most efficient configuration from the heat transfer point of view is the one with moving prism at $\mathrm{m}^{*}=0.91$. For instance, the electric power needed to keep the aluminum block at a surface temperature $60^{\circ} \mathrm{C}(\operatorname{Re} 320)$ is $307 \mathrm{~W}$ for $\mathrm{m}^{*}=0.91,280 \mathrm{~W}$ for $\mathrm{m}^{*}=0.70$, and $265 \mathrm{~W}$ for $\mathrm{m}^{*}=0.56$. That is, the heat transfer difference between the cases with highest and lowest $\mathrm{m}^{*}$ was $42 \mathrm{~W}$ (a $16 \%$ difference). Interestingly enough, the thermal power associated to the case with the fixed prism was $278 \mathrm{~W}$, which is in between the limits set up by the highest and 

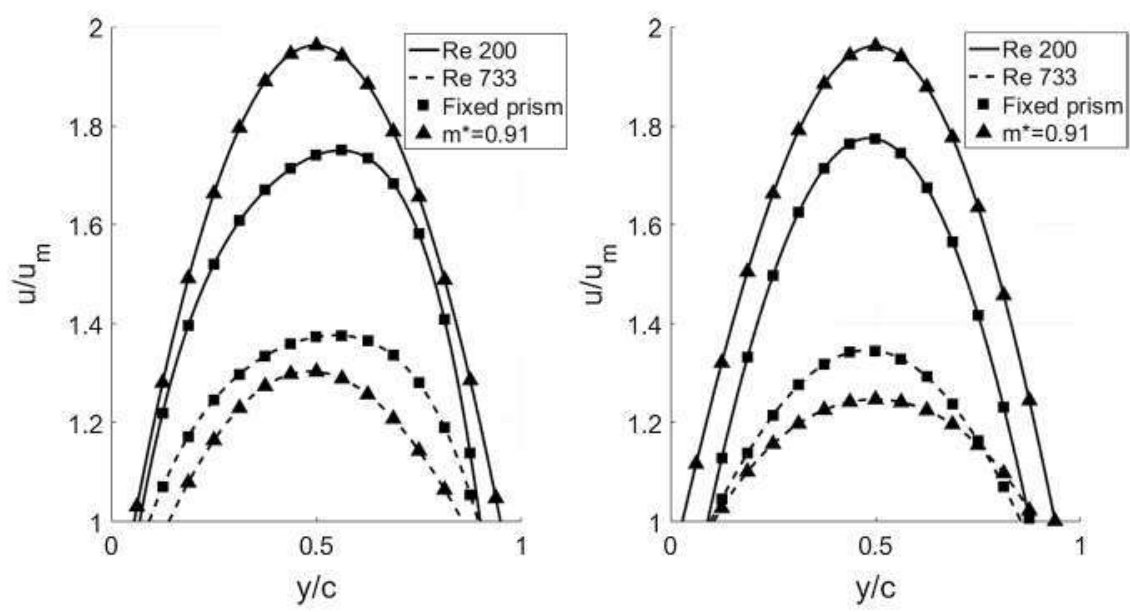

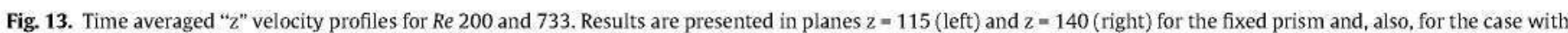
$\mathrm{m}=0.91$.

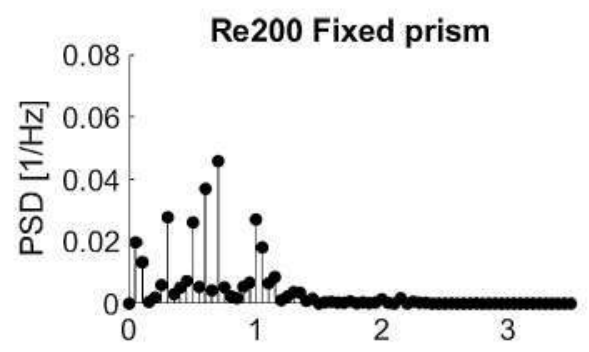

$[\mathrm{Hz}]$

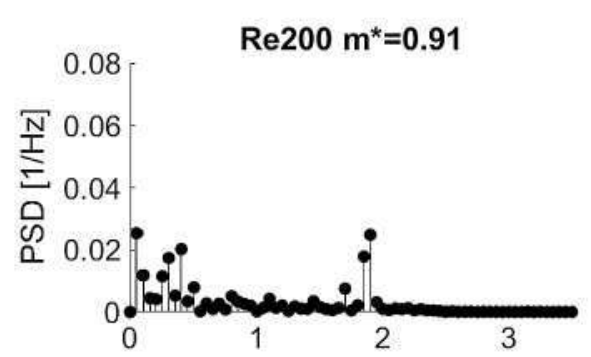

$[\mathrm{Hz}]$

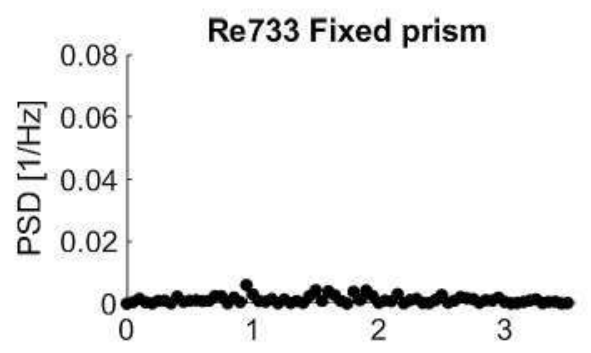

$[\mathrm{Hz}]$

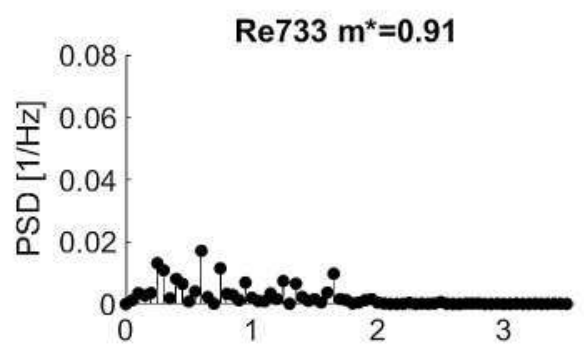

$[\mathrm{Hz}]$

Fig. 14. Power spectra density plots of the downstream velocity in the channel centerline for the isotherm fixed prism at $R e 200$ and $R e$ 733.
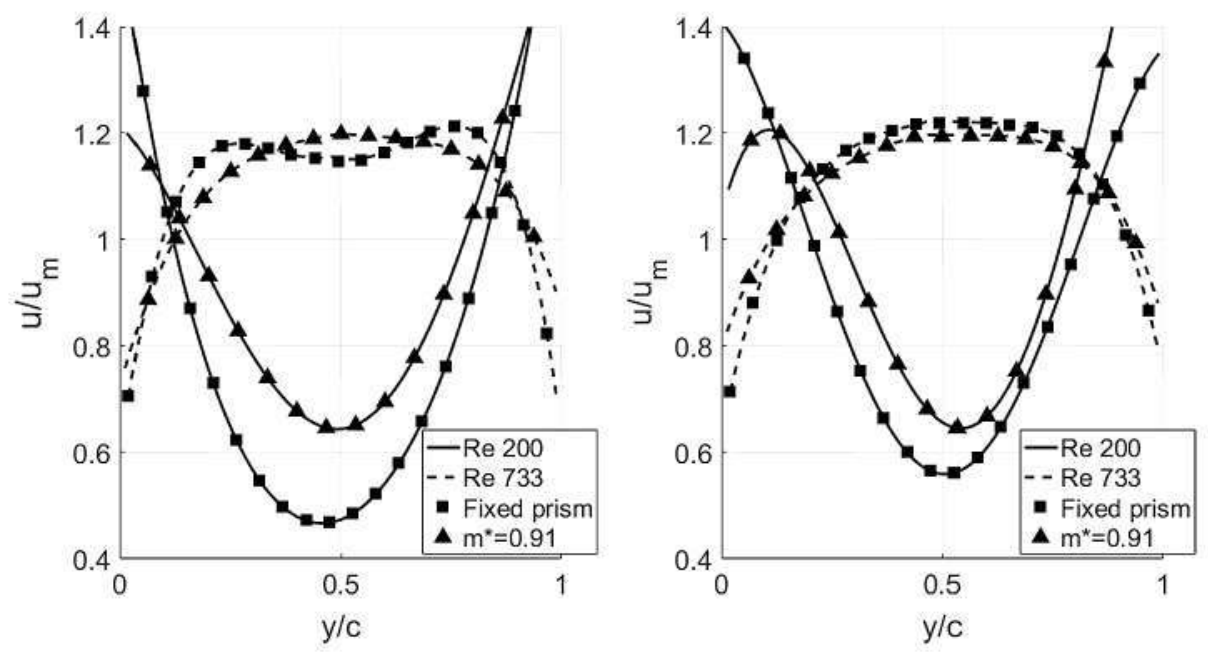

Fig. 15. Counterpart of Fig. 11 but considering now the thermal case. 

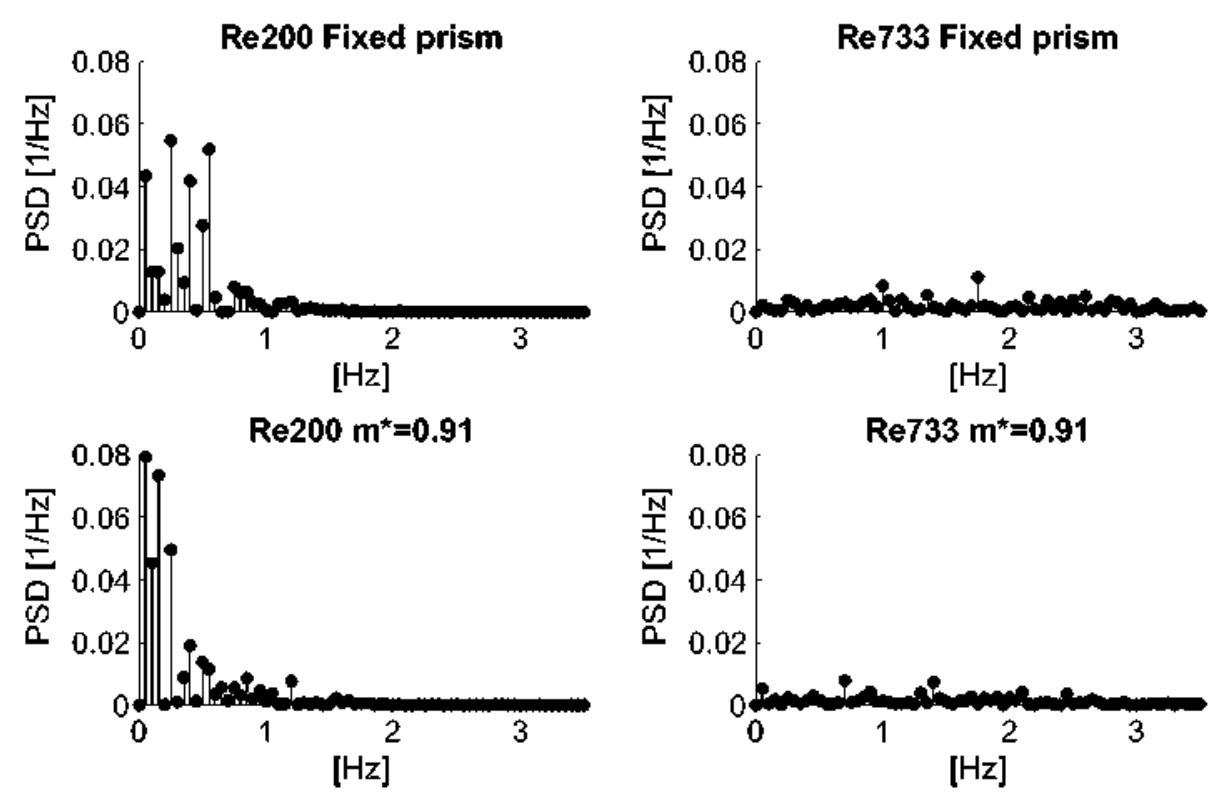

Fig. 16. Counterpart of Fig. 12 but considering now the thermal case.

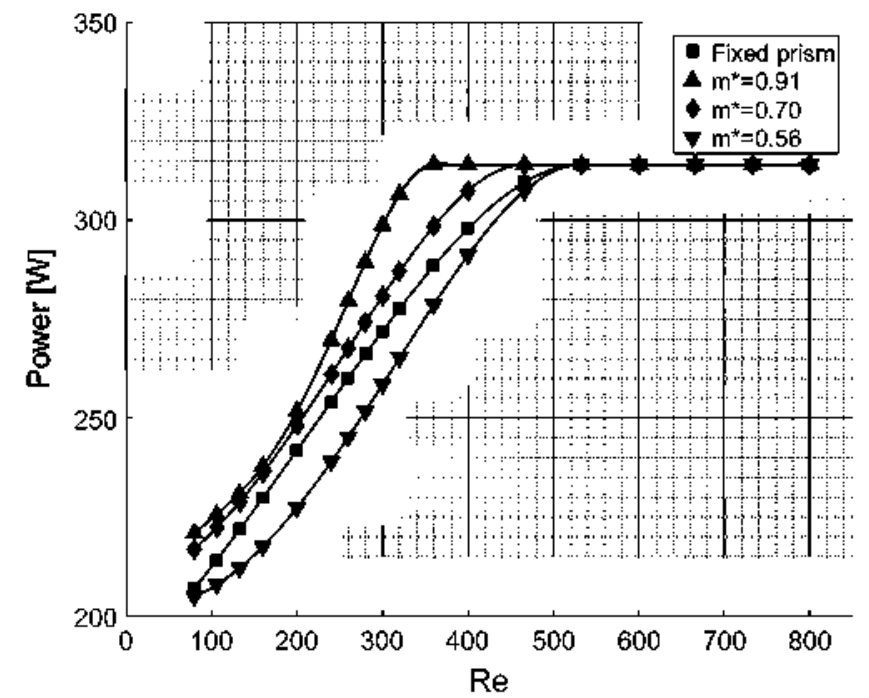

Fig. 17. Electric power supplied by the DC unit to the aluminum walls (heat transfer to the fluid) as a function of $R e$ and $\mathrm{m}^{+}$for constant wall temperature. The case of the fixed prism is also included for comparison purposes.

lowest $\mathrm{m}^{*}$. As it can be observed in Fig. 16, this behavior is consistently observed for Re up to 400 . This suggests that not all types of prism motion improve heat transfer as compared to the case of the fixed prism. In fact, the case with $\mathrm{m}^{*}=0.56$ yields a heat transfer consistently smaller than the case with the fixed prism all over the discussed Re range. The authors think that this is related with the flow topologies generated by the prism motion and their interaction with the buoyant plumes that originate at the solid aluminum walls. ldeally, the best study option for this effect would be to perform a PIV based analysis of these structures, but this appears to be impossible owing to the fact that the aluminum walls are opaque. Then, the only feasible approach seems to be a CFD based one that is out of the scope of this work (it will be addressed by the authors in a future work). These experimental results are, nevertheless, somewhat unexpected because, in a sense, it would be tempting to regard a fixed prism as a system characterized by an infinite buoyant force that leads to an infinite restoring force that suppresses all possible motion. Within this perspective, the fixed prism could be considered as the asymptotic limit of a sequence of prisms in which the buoyant force keeps growing. However, in view of the observed experimental results this does not appear to be the correct approach. Possibly, what happens is that the presence of an additional equation of motion for the cases in which the prism moves changes the system dynamics completely.

Fig. 18 presents the time average of 300 PIV frames $20 \mathrm{~s}$ of experiment) for $\operatorname{Re} 200$. Both the dimensionless stream-wise $\mathrm{U}$ velocity and the cross-wise velocity $V$ are plotted for $\mathrm{EC} \# 4$ (the thermal fixed prism) and $\mathrm{EC} \# 6$ (the thermal moving prism with $\mathrm{m}^{*}=0.91$ ). The two upper subplots (stream-wise velocity) show a similar topology: the actual values of the time-averaged velocity might be slightly different but the global behavior is basically the same. However, the two lower subplots that depict the crosswise velocity are different. In particular, the left one (fixed prism) shows that the average cross-wise velocity near the channel walls is small: it has different shades of green color that means that this

Table 3

$\mathrm{Nu}$ as a function of $R e$ and $\mathrm{m}^{*}$ for the constant wall temperature case.

\begin{tabular}{|c|c|c|c|c|}
\hline $\operatorname{Re}$ & $\mathrm{m}^{+}=0.56$ & $\mathrm{~m}^{+}=0.70$ & $\mathrm{~m}^{+}=0.91$ & Fixed prism \\
\hline 80 & 30.7 & 32.6 & 33.3 & 31.9 \\
\hline 133 & 31.7 & 332 & 32.0 & 31.7 \\
\hline 160 & 31.1 & 33.3 & 32.8 & 32.3 \\
\hline 200 & 30.8 & 32.6 & 34.7 & 33.0 \\
\hline 240 & 31.1 & 33.7 & 36.6 & 34.6 \\
\hline 300 & 33.6 & 38.3 & 40.0 & 37.3 \\
\hline 360 & 36.5 & 39.6 & 43.2 & 40.1 \\
\hline
\end{tabular}



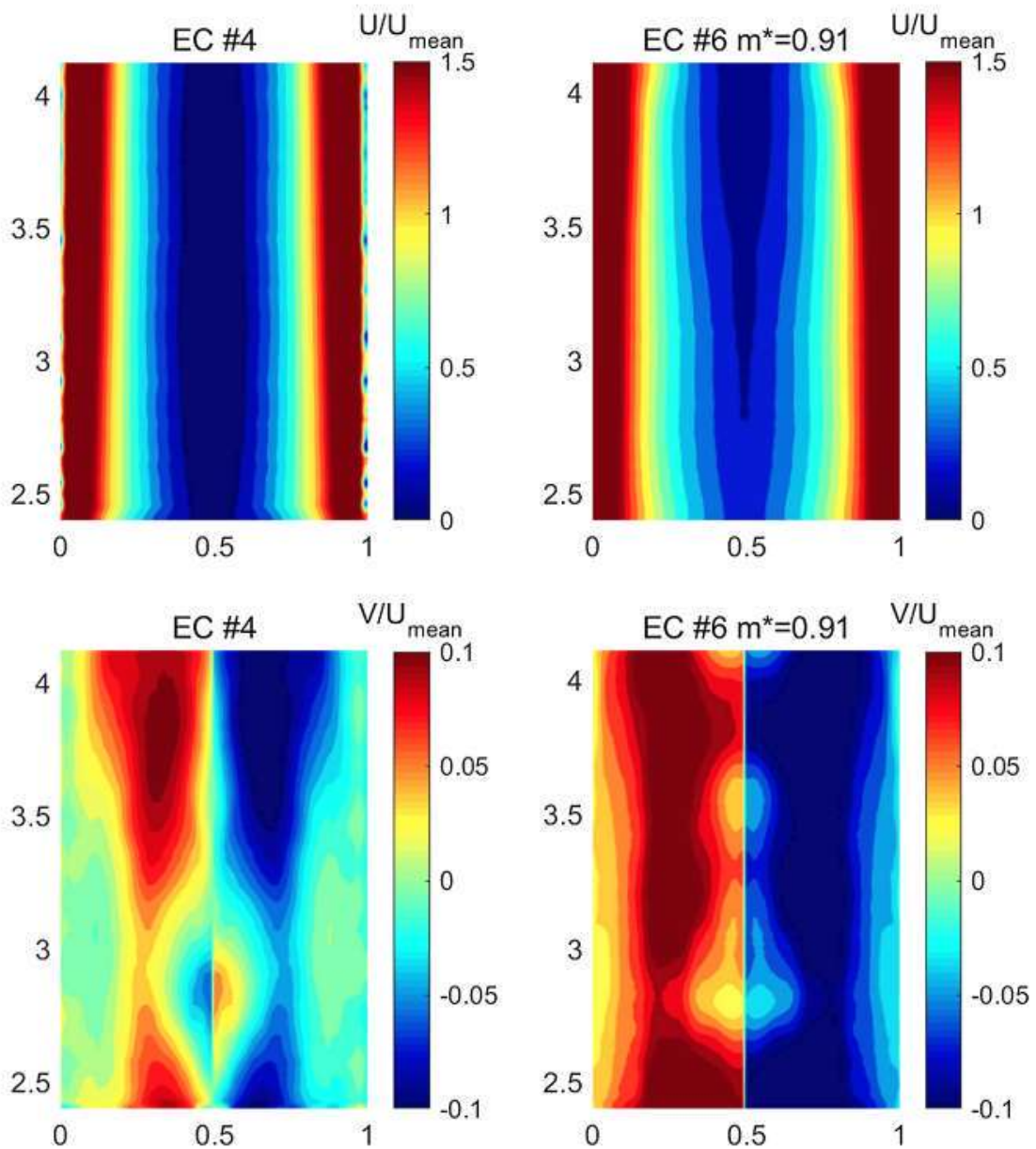

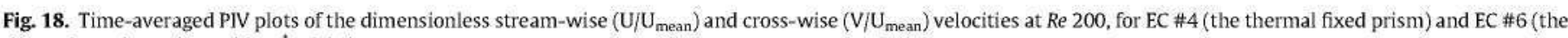
thermal moving prism with $\mathrm{m}^{*}=0.91$ ).

average velocity value is around zero (see the color bar to the right of the plot). On the other hand, see the lower right subplot, the case with the moving prism shows that the time-averaged cross wise velocity is positive the vicinity of the channel left wall (it has shades of yellow-orange ${ }^{1}$ color) that means that its direction is from the left wall towards the channel centerline. At the same time, it could be observed that the time-averaged cross-section velocity is negative in the vicinity of the channel right wall (it has shades of blue color) that means that, again, its direction is from the (right) wall towards the channel centerline. That is, the presence of the moving prism modifies the topology of the time-averaged cross wise velocity in the sense that it promotes motion from the walls towards the channel centerline, thereby promoting the transport of heat from the walls into the bulk flow. The fact that this cross-wise velocity is small when compared to the stream-wise velocity imposed a limit on the additional amount of heat that can be actually transferred from the channel walls into the main body of fluid.

Once the maximum power level was reached, further increments of Re led to a decrease in the wall temperature because of the growing heat transfer rate. This can be observed in Fig. 19 where the average wall temperature is presented as a function of $R e$ and $\mathrm{m}^{*}$ (including, also, the fixed prism case). The actual measurements of the 10 thermocouples as function of Re for the cases of $\mathrm{m}^{*}=0.91$ and fixed prism are presented in Table 4 for four representative $\operatorname{Re}(106,200,260$, and 733$)$. At the highest $\operatorname{Re}$, the lar-

\footnotetext{
1 For interpretation of color in Fig. 18, the reader is referred to the web version of this article.
}

gest temperature difference in the aluminum walls was $4 \mathrm{C}$. It is also worth noting that the larger the $R e$, the more similar are the results of $\mathrm{m}^{*}=0.70, \mathrm{~m}^{*}=0.56$ and fixed prism, while the wall temperature for $\mathrm{m}^{*}=0.91$ keeps consistently lower. Again, this sug-

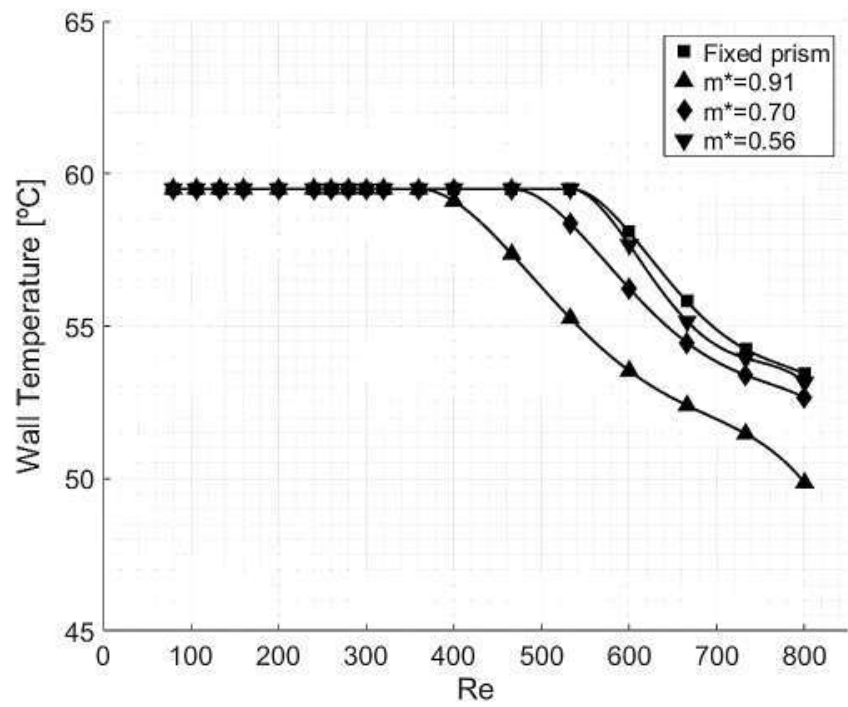

Fig. 19. Average aluminum wall temperature as a function of $R e$ and $m$ once the threshold level of electric power supply ( $315 \mathrm{~W}$ ) has been reached. The case of the fixed prism is also included for comparison purposes. 
Table 4

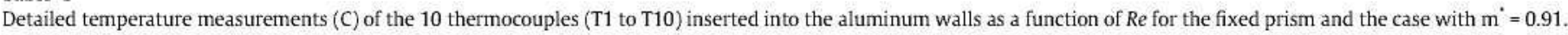

\begin{tabular}{|c|c|c|c|c|c|c|c|c|}
\hline & \multicolumn{2}{|c|}{$\operatorname{Re} 106$} & \multicolumn{2}{|c|}{$\operatorname{Re} 200$} & \multicolumn{2}{|c|}{$\operatorname{Re} 260$} & \multicolumn{2}{|c|}{$\operatorname{Re} 733$} \\
\hline & Fix. & $\mathrm{m}^{\circ}=0.91$ & Fix. & $\mathrm{m}^{*}=0.91$ & Fix. & $\mathrm{m}^{*}=0.91$ & Fix. & $\mathrm{m}^{*}=0.91$ \\
\hline $\mathrm{T} 1$ & 57.9 & 60.4 & 60.3 & 59.0 & 58.6 & 60.5 & 53.1 & 51.6 \\
\hline $\mathrm{T} 2$ & 57.8 & 60.0 & 59.9 & 58.5 & 58.1 & 59.5 & 52.7 & 51.0 \\
\hline T3 & 58.3 & 59.4 & 59.6 & 58.8 & 58.9 & 60.0 & 55.0 & 53.0 \\
\hline $\mathrm{T} 4$ & 58.1 & 59.2 & 59.3 & 58.5 & 58.5 & 59.7 & 54.7 & 52.8 \\
\hline T5 & 57.4 & 59.4 & 59.3 & 57.9 & 57.1 & 58.8 & 50.8 & 49.1 \\
\hline T6 & 57.5 & 59.9 & 59.5 & 58.1 & 57.5 & 59.1 & 50.7 & 49.4 \\
\hline T7 & 58.8 & 60.6 & 60.5 & 59.4 & 58.9 & 60.1 & 53.2 & 50.4 \\
\hline T8 & 58.8 & 60.8 & 60.5 & 59,3 & 59.2 & 60.2 & 53.4 & 50.3 \\
\hline T9 & 58.3 & 59.3 & 59.5 & 58.6 & 58.7 & 59.8 & 55.1 & 53.0 \\
\hline T10 & 58.7 & 59.9 & 59.8 & 59.3 & 59.1 & 60.5 & 55.4 & 53.7 \\
\hline
\end{tabular}

Table 5

$\mathrm{Nu}$ as function of $\mathrm{Re}$ and $\mathrm{m}^{*}$ for the constant wall heat transfer case.

\begin{tabular}{|c|c|c|c|c|}
\hline $\mathrm{Re}$ & $\mathrm{m}^{\circ}=0.56$ & $\mathrm{~m}^{\circ}=0.70$ & $\mathrm{~m}^{*}=0.91$ & Fixed prism \\
\hline 533 & 41.3 & 44.0 & 47.4 & 44.0 \\
\hline 600 & 42.1 & 47.0 & 50.8 & 46.1 \\
\hline 666 & 44.3 & 48.5 & 51.8 & 47.7 \\
\hline 733 & 44.7 & 50.6 & 54.2 & 49.1 \\
\hline 800 & 46.9 & 53.0 & 59.4 & 50.9 \\
\hline
\end{tabular}

Table 6

RMS of the dimensionless water temperature for the case of constant wall temperature as a function of $R e$ and $m$.

\begin{tabular}{|c|c|c|c|c|}
\hline & $\mathrm{m}^{*}=0.56$ & $\mathrm{~m}=0.70$ & $\mathrm{~m}^{*}=0.91$ & Fixed prism \\
\hline $\operatorname{Re} 80$ & 3.51 & 3.82 & 3.67 & 2.97 \\
\hline $\operatorname{Re} 133$ & 4.22 & 4.60 & 4.33 & 4.24 \\
\hline $\operatorname{Re} 160$ & 4.11 & 4.56 & 3.96 & 3.53 \\
\hline $\operatorname{Re} 200$ & 3.89 & 3.11 & 2.51 & 3.36 \\
\hline $\operatorname{Re} 240$ & 3.37 & 2.65 & 2.63 & 2.59 \\
\hline $\operatorname{Re} 300$ & 1.39 & 1.60 & 1.41 & 1.98 \\
\hline $\operatorname{Re} 360$ & 1.19 & 1.25 & 0.94 & 1.80 \\
\hline
\end{tabular}

Table 7

RMS of the dimensionless water temperature for the case of constant wall heat transfer as a function of $R e$ and $m{ }^{\circ}$.

\begin{tabular}{|c|c|c|c|c|}
\hline & $\mathrm{m}^{*}=0.56$ & $\mathrm{~m}^{\prime}=0.70$ & $\mathrm{~m}^{*}=0.91$ & Fixed prism \\
\hline $\operatorname{Re} 533$ & 0.74 & 0.72 & 0,47 & 1.30 \\
\hline $\operatorname{Re} 600$ & 0.76 & 0.70 & 0.52 & 0.72 \\
\hline $\operatorname{Re} 666$ & 0.55 & 0.51 & 0.46 & 0.60 \\
\hline $\operatorname{Re} 733$ & 0.48 & 0.47 & 0.46 & 0.56 \\
\hline $\operatorname{Re} 800$ & 0.60 & 0.49 & 0.31 & 0.52 \\
\hline
\end{tabular}

gests that the dynamics of the system influences significantly the heat transfer rate. In this regard, the behavior of the cross-wise time averaged velocity in the vicinity of the walls is qualitatively similar to the one shown in Fig. 18.

$\mathrm{Nu}$ as a function of $\mathrm{Re}$ and $\mathrm{m}^{*}$ has also been computed for the cases presented in Fig. 19 and the results are shown in Table 5. These results correlate with the following expression: $\mathrm{Nu}=4.07 \mathrm{Re}^{0.40} \mathrm{~m}^{+0.37}$. As compared to the clean channel case (see Table 2) the improvement on $\mathrm{Nu}$ is about $100 \%$. As compared to the fixed prism case (see Table 5) the improvement on $\mathrm{Nu}$ is about $20 \%$

Another aspect to be analyzed is the spatial variation of temperature on the plane where the thermocouples were inserted into the fluid. To quantify this variation, the rms of the reconstructed 2D dimensionless temperature distribution downstream of the prism has been computed (following the procedure illustrated in Fig. 10) and the results are presented in Tables 6 and 7 for the cases of constant wall temperature and constant wall heat transfer cases respectively. When looking at the results of Table 6 , it could be observed that from $\operatorname{Re} 200$ onwards the rms of the temperature signal for $\mathrm{m}^{*}=0.91$ case is consistently lower than in the other cases. This suggests that local mixing is achieved more efficiently in this particular case of $\mathrm{m}^{*}=0.91$ which leads to a better global mixing and higher $\mathrm{Nu}$, as it is indeed the case. That is, the results presented in Table 6, that were obtained processing local temperature data, support the results of Fig. 17 that were of a global nature. For the constant wall heat transfer case, see Table 7, the trend is the same and the rms of the temperature signal for $\mathrm{m}^{*}=0.91$ is the lowest of all.

\section{Conclusions}

An experimental study has been performed on the heat transfer rate in a passive system in which the flow is disturbed (so as to promote mixing) due to fluid-body interaction effects. The test setup consisted of a square section channel $(25 \mathrm{~mm} \times 25 \mathrm{~mm})$ in which a buoyant tethered prism was placed. All around the prism, heated aluminum walls transferred thermal energy to the fluid. 
The Reynolds number based on the prism cross section length $(10 \mathrm{~mm})$ was varied between 80 and 800 . Three prism-to-water density ratio were considered: $m^{*}=0.56,0.70$ and 0.91 . The clean channel case and the case with a fixed prism were also addressed for comparison purposes. The conclusions of the study could be stated as follows.

- In the configuration that has been studied, the presence of either a fixed or a moving buoyant prism always improved the heat transfer rate as compared to the clean channel case. In the case of the moving prism, the improvement on $\mathrm{Nu}$ was as high as $100 \%$. In the case of the fixed prism, the maximum improvement was $66 \%$.

- The reason for the improvement could be associated to the fact that both the fixed and the moving prisms modify substantially the flow topology in a way so as to enhance mixing. It should be noted that the length of the wall that was heated was $90 \mathrm{~mm}$ while the prism cross section length was $10 \mathrm{~mm}$. If the heated portion of the wall is longer, it is expected that the flow tends to attain its limiting Poiseuille type behavior and the enhancement effect should die away further downstream of the prism.

- Not all moving prisms generated heat transfer rates higher than the case of the fixed prism. In fact, the case with $\mathrm{m}^{*}=0.56$ (the lowest one) consistently yielded the lowest $N u$ values. This suggests that not all types of prism motions improve heat transfer in the same way. The reason, again, could be ascribed to the different flow topologies that appear associated to the different values of $\mathrm{m}^{*}$

- For the configuration and parametric range presented in this study, the best configuration was the one with $\mathrm{m}^{*}=0.91$.

- The 2D temperature profiles in the channel sections downstream of the moving prism have been analyzed and it has been found that the lowest rms correspond to the case with $\mathrm{m}^{*}=0.91$. This, again, supports the idea that this specific configuration promotes mixing in a way that is more efficient than others with lower $\mathrm{m}^{*}$, and also more efficient than the fixed prism case.

- From the fundamental Fluid Mechanics point of view, the present study poses some questions that will need further analysis in the future. One of these is why depending on the value of $\mathrm{m}^{*}$, the prism in self sustained motion may either improve or deteriorate the heat transfer as compared to the fixed prism.

- From the engineering applications context, all that has been presented suggests that when devising practical applications, these types of passive configurations, that are conceptually very simple, might have some advantages over active systems when dealing with mixing at low Reynolds numbers. Specifically, an active system needs the presence of a motor with independent power supply that moves impeller type (or other) devices. This, on one hand, leads to a more complex system and, on the other, requires some mechanical connection between the external motor and the internal propeller-like device which might cause liquid leakage outside the channel (pipe). On the other hand, the external motor can control the amount of mechanical work that can be put into the fluid so the mixing can be more efficient. Thereby, the final selection of the system, either active or passive, might be the outcome of a compromise between system complexity and actual efficiency. In any case, the present study shows that the passive option could be, in some cases, an acceptable solution in terms of simplicity and efficiency.

\section{Acknowledgements}

The authors were funded by the Spanish Ministry of Economy and Competitiveness (Ministerio de Economia y Competitividad) under research contract DPI2013-45207. They gratefully acknowledge this support.

\section{References}

[1] B. Celik, M. Raisee, A. Beskok, Heat transfer enhancement in a slot channel via a transversely oscillating adiabatic circular cylinder, Int. J. Heat Mass Transf. 53 (2010) 626-634

[2] W.S. Fu, B.H. Tong, Effects of eccentricity of cylinder and blockage ratio on heat transfer by an oscillating cylinder in a channel flow, Int. Comm. Heat Mass Transf. 30 (2003) 401-412.

[3] W.S. Fu, B.H. Tong, Numerical investigation of heat transfer of a heated channel with an oscillating cylinder, Numer. Heat Transf. 43 (2003) 639-658.

[4] Y.T. Yang, C.H. Chen, Numerical simulation of turbulent fluid flow and heat transfer characteristics of heated blocks in the channel with an oscillating cylinder, Int. J. Heat Mass Transf. 51 (2008) 1603-1612.

[5] J. Ghazanfarian, M.R.H. Nobari, A numerical study of convective heat transfer from a rotating cylinder with cross-flow oscillation, Int. I. Heat Mass Transf. 52 (2009) 5402-5411.

[6] M.R.H. Nobari, ]. Ghazanfarian, Convective heat transfer from a rotating cylinder with inline oscillation, Int. J. Therm. Sci. 49 (2010) 2026-2036.

[7] T.S. Pottebaum, M. Gharib, Using oscillations to enhance heat transfer for a circular cylinder, Int. J. Heat Mass Transf. 49 (2006) 3190-3210.

[8] M. Reyes, A. Velazquez, E. Martin, J.R. Arias, Experimental study on the confined 3D laminar flow past a square prism with a high blockage ratio, Int. J Heat Fluid Flow 44 (2013) 444-457.

[9] M. Reyes, A. Velazquez, J.R. Arias, E. Martin, Experimental study on the flow regimes past a confined prism undergoing self-sustained oscillations, int. J. Heat Fluid Flow 54 (2015) 65-76.

[10] M. Schafer, M.S. Turek, Benchmark computations of laminar flow around a cylinder, in: E.H. Hirshel (Ed.), Flow Simulation with High Performance Computers II, Notes in Fluid Mechanics, vol. 52, Vieweg, 1996, pp. 547-566.

[11] D.T. Sandwell, Biharmonic spline interpolation of GEOS-3 and SEASAT altimeter data, Geophys. Res. Lett. 2 (1987) 139-142.

[12] F.P. Incropera, D.P. DeWitt, Introduction to Heat Transfer, John Wiley \& Sons, New York, 1996.

[13] E. Martin, A. Velazquez, Effect of span length and temperature on the 3-D confined flow around a vortex promoter, Int. J. Heat Fluid Flow 54 (2011) 1173-1185. 